\title{
Recommendations for stronger biochar research in soil biology and fertility
}

\author{
Y. J. Cai ${ }^{1}$ - Y. S. Ok ${ }^{2}$ - J. Lehmann ${ }^{3,4,5} \cdot$ S. X. Chang ${ }^{1,6}$ \\ Published online: 23 February 2021 \\ (C) The Author(s), under exclusive licence to Springer-Verlag GmbH, DE part of Springer Nature 2021
}

Research on biochar, a product from the pyrolysis of biomass under limited or no oxygen conditions, has gained momentum in developing applications in areas ranging from improvement of soil fertility to pollution remediation, and from mitigation of climate change to use in the manufacturing of healthcare products such as supercapacitors (Ok et al. 2015; Wu et al. 2019). The burgeoning interest in biochar applications followed some of the early work on using biochar as a soil amendment (the current use of the biochar concept) (Woods et al. 2006). The number of publications with the term "biochar" (whether biochar as a soil amendment or a fuel) in the title, abstract, or keywords has gone from just one publication in 1998 to 3210 in 2020, based on a search on Web of Science (accessed on February 1, 2021). Glaser et al. (2002), published in Biology and Fertility of Soils (BFSO), provided one of the earliest studies on the subject by reviewing the effect of combustion procedures on the physical and chemical properties of biochar (using the term "charcoal" at the time). Five papers published in 2007 that dealt with biochar's environmental applications stood out as highly influential; those papers dealt with biochar as a soil amendment (Chan et al. 2007; Rondon et al. 2007; Warnock et al. 2007), or as a carbon-negative

S. X. Chang

sxchang@ualberta.ca

1 State Key Laboratory of Subtropical Silviculture, Zhejiang A\&F University, Hangzhou, China

2 Korea Biochar Research Center, APRU Sustainable Waste Management Program \& Division of Environmental Science and Ecological Engineering, Korea University, Seoul, Republic of Korea

3 Soil and Crop Sciences, School of Integrative Plant Science, Cornell University, Ithaca, NY 14853, USA

4 Institute for Advanced Study, Technical University of Munich, Garching, Germany

5 Cornell Atkinson Center for Sustainability, Ithaca, NY 14853, USA

6 Department of Renewable Resources, University of Alberta, Edmonton, Alberta, Canada renewable energy source (Lehmann 2007a; Lehmann $2007 b$ ). Those pioneering work strongly promoted biochar research, with the number of publications on biochar exponentially increased in the years that followed. The Rondon et al. (2007) biochar paper, one of the five papers mentioned above, was published in BFSO. Clearly, BFSO is one of the pioneering journals publishing research on biochar as a soil amendment; to date, 68 papers have been published in BFSO where biochar is included as at least one of the treatments.

The number of publications with a focus on biochar exponentially increased over the last couple of decades; many of those publications are focused on biochar's agronomic and environmental benefits, with "biochar and global climate change" and "soil quality and plant growth" as some of the main research topics (Wu et al. 2019). Accompanying those trends, submissions of biochar-focused research papers to BFSO have significantly increased in recent years. Unfortunately, many of those biochar-related submissions suffer numerous deficiencies, and, as a result, are rejected without review. The purpose of this editorial is, therefore, to provide some guideline to authors submitting a biocharrelated paper to BFSO as to what constitutes strong biochar research, so that the chances of having the manuscript reviewed and eventually accepted can be improved.

Biochar properties are highly dependent on the pyrolysis condition and the feedstock (biomass used to produce the target biochar) type used for its production (Schimmelpfennig and Glaser 2012). The key pyrolysis condition affecting biochar properties is the temperature used for pyrolysis but also includes the heating rate, the residence time, and the purging gas used (Ahmad et al. 2014). The feedstock type used may range from crop residues to manure and sewage sludge. Biochar properties can also be altered by different modification methods that are applied before or after pyrolysis (Rajapaksha et al. 2016). The widely variable biochar types (and the resulting properties) and the large number of potential applications mean that results from biochar research are often highly variable. Research is needed to help us understand the 
utility of biochar to achieve the range of ecological goods and services (Amonette et al. 2021) that can be derived when applied to soils that have equally diverse properties. Many researchers who are new to biochar research are often intimidated by the large number of variables that they have to consider in designing their experiments and at the end may make wrong decisions in their biochar research in terms of what to study and how to study it. We suggest the following as basic guidelines for conducting scientifically sound biochar research related to soil biology and fertility, and for properly preparing a paper for publication.

1. Biochar research, as with any other line of research, should be based on a well-defined scientific question. As the number of researchers conducting and publishing biochar-related research is large, it is essential that authors are up-to-date with the literature and can demonstrate the novelty of the research in the paper being submitted for publication, rather than repeating research that has already been conducted. Biochar research needs to move from descriptive to mechanistic. For example, linking the effects of biochar on nitrous oxide $\left(\mathrm{N}_{2} \mathrm{O}\right)$ emissions to changes in the composition of bacteria communities responsible for denitrification (Lévesque et al. 2020) to the composition of functional groups of biochar (Yuan et al. 2021), or to variations in $\mathrm{N}_{2} \mathrm{O}$-producing processes and related functional microbes (Duan et al. 2018), provides an understanding of the mechanisms involved in changes in $\mathrm{N}_{2} \mathrm{O}$ emissions. Mechanistic understanding gained from biochar research will allow us to extrapolate findings from one site to another. Lack of novelty is the single-most frequently used reason to reject a biochar research-related manuscript with or without review.

2. Biochars used in a submitted manuscript should be well characterized, and the conditions used for producing the biochars should be documented in detail, as biochar properties are affected by the conditions used for its production. Proper documentation of biochar properties and the associated production condition will facilitate comparisons across different studies. At a minimum, proximate (the moisture, ash, volatile matter and fixed carbon concentrations) and ultimate analyses (the carbon, nitrogen, hydrogen, oxygen, and sulfur concentrations) of biochar samples should be conducted and reported, and information such as $\mathrm{pH}$, surface area, cation exchange capacity, and dissolved organic $\mathrm{C}$ and $\mathrm{N}$ concentrations should also be provided. Information on such biochar properties can aid in the interpretation of results from field-, greenhouse-, or laboratory-based studies. Production condition to be provided should include the pyrolysis temperature, the heating rate, the residence time, and the purging gas used (if applicable). Use of standard biochars has been suggested to improve the replicability of findings from biochar research, and the UK Biochar Research Centre (UKBRC) at the University of Edinburgh is offering free standardized biochar samples for use by the research community (Masek et al. 2018).

3. The type of feedstock used for producing the biochar should be clearly stated. The feedstock used should either represent biomass that can be sustainably obtained if the research results are to be scaled up from the plot to the field or regional level (system-oriented research, Amonette et al. 2021), or be one that would allow the examination of fundamental mechanisms to useful questions (mechanistic research). Some authors claim novelty of their research based on them being the first to use a particular feedstock; however, using a unique feedstock such as biomass of a regional plant species for the first time is not a scientific novelty in biochar research.

4. Similar to the characterization of biochars, the study site or soil should be characterized in detail as well, as the biochar effect on soil depends on both biochar and soil properties. Information such as soil type, climate, hydrology, and land-use type, as well as basic soil properties should be documented. For greenhouse or field studies, the type of crop or plant species grown, the greenhouse or climate condition of the test site, the method used to apply and incorporate the biochar into the soil, depth of biochar incorporation, and agronomic practices such as tillage methods, rate of conventional fertilizer applications, and rate of irrigation (if applicable) should be reported (Jeffery et al. 2015). Careful characterization and documentation of biochar and soil properties, and their variability, will help with future synthesis work.

5. Studies involving a single biochar or a single soil should be avoided. For studies involving a single biochar or a single soil, it is less likely that a mechanistic understanding of the biochar effect can be gained. Systematically varying soil (e.g., its texture, $\mathrm{pH}$, or $\mathrm{C}$ content) and biochar properties (e.g., its $\mathrm{pH}$, pore volume, or proportion of fused aromatic rings) will help address wellformulated hypotheses. While laboratory- or greenhouse-based research is often useful for mechanistic studies, field-based research should increasingly be encouraged over laboratory- or greenhouse-based research, so that the research is applicable to specific site conditions and can be conducted over the long term. The emphasis should be to understand the mechanisms involved in biochar effects on soil properties and processes, rather than on just documenting the effect itself.

6. Proper controls should be included, including both negative and positive controls as discussed in Jeffery et al. (2015). A negative control is one that has no biochar applied while a positive control is one that has the 
feedstock applied (either on an equivalent mass or resource basis) or some other forms of a positive control. Including different controls will allow us to isolate the mechanism that causes the biochar effect on soil properties and processes or crop productivity on a material or systems level. Jeffery et al. (2015) proposed that multiple positive controls could be used to test multiple competing hypotheses in one experiment so as to improve the efficiency of hypothesis testing.

7. The number of replications to include in the experimental design should be carefully considered. Biochar application to the soil may increase the spatial variability of soil properties and processes being evaluated and the number of replications to be used should be sufficient to reduce the probability of making a type II error (failing to reject the null hypothesis when it is false). While the number of replications to be used is ideally determined by the spatial variability of the study site or sites, which may or may not be feasible prior to setting up an experiment, more than three replicates and ideally at least five or six replicates are recommended. As much as possible, the spatial variability within a research plot should be quantified, instead of reporting the results based on a composite sample from a plot.

8. Long-term data collection should be encouraged. A minimum of 2 years of data should be collected from a project and reported in a publication. The long-lasting nature of biochar in the soil will require long-term research to fully understand the impact of biochars on soil properties and processes. Long-term data will help to distinguish the effect due to unique biochar properties from those that are related to the short-term disturbance (e.g., caused by the incorporation of biochar into the soil), fertilization, or liming effect that the biochar application may have (Jeffery et al. 2015). Long-term research plots could be revisited every few years so that the longevity of biochar effects can be ascertained, as biochar aging will change its own properties and its effect on soil properties and processes (Wang et al. 2020).

9. In evaluating biochar effects on the soil, both positive and negative effects need to be accounted for, and especially risks need to be clearly documented. As an example, biochar may reduce $\mathrm{N}_{2} \mathrm{O}$ but increase $\mathrm{CO}_{2}$ emissions; therefore, the effect of biochar on greenhouse gases $\left(\mathrm{CO}_{2}, \mathrm{~N}_{2} \mathrm{O}\right.$ and $\left.\mathrm{CH}_{4}\right)$ should be discussed in an unbiased way to evaluate the combined effect of biochar on greenhouse gas emissions.

10. The negative effects from biochar application such as the potential introduction of contaminants should also be encouraged to be addressed in future research. A lifecycle analysis approach should be strongly encouraged to assess the potential disadvantages as well as the ecological and economic benefits of the soil application of biochars, so that the proper conclusion can be made.

Readers are encouraged to read Jeffery et al. (2015), where a detailed discussion of standardized experimental techniques and reporting of results is provided to allow proper crossstudy comparison and policy-relevant conclusions to be made. Jeffery et al. (2015) is likely still the most relevant paper on guiding biochar research in environmental sciences. We would also like to note that it is not intended for a biochar researcher to follow all of the above recommendations in every experiment, but hopefully the recommendations will be followed as much as practical as they offer a way forward for improving biochar research related to soil biology and fertility.

\section{References}

Ahmad M, Rajapaksha AU, Lim JE, Zhang M, Bolan N, Mohan D, Vithanage M, Lee SS, Ok YS (2014) Biochar as a sorbent for contaminant management in soil and water: a review. Chemosphere 99: $19-33$

Amonette JE, Blanco-Canqui H, Hassebrook C, Laird DA, Lal R, Lehmann J, Page-Dumroese D (2021) Integrated biochar research: a roadmap. J Soil Water Conserv 76:24A-29A

Chan KY, Van Zwieten L, Meszaros I, Downie A, Joseph S (2007) Agronomic values of greenwaste biochar as a soil amendment. Aust J Soil Res 45:629-634

Duan P, Zhang X, Zhang Q, Wu Z, Xiong Z (2018) Field-aged biochar stimulated $\mathrm{N}_{2} \mathrm{O}$ production from greenhouse vegetable production soils by nitrification and denitrification. Sci Total Environ 642: 1303-1310

Glaser B, Lehmann J, Zech W (2002) Ameliorating physical and chemical properties of highly weathered soils in the tropics with charcoala review. Biol Fertil Soils 35:219-230

Jeffery S, Bezemer TM, Cornelissen G, Kuyper TW, Lehmann J, Mommer L, Sohi SP, van de Voorde TFJ, Wardle DA, van Groenigen JW (2015) The way forward in biochar research: targeting trade-offs between the potential wins. GCB Bioenergy 7:1-13

Lehmann J (2007a) Bio-energy in the black. Front Ecol Environ 5:381-387

Lehmann J (2007b) A handful of carbon. Nature 447:143-144

Lévesque V, Rochette P, Hogue R, Jeanne T, Ziadi N, Chantigny MH, Dorais M, Antoun H (2020) Greenhouse gas emissions and soil bacterial community as affected by biochar amendments after periodic mineral fertilizer applications. Biol Fertil Soils 56:907-925

Masek O, Buss W, Sohi S (2018) Standard biochar materials. Environ Sci Technol 52:9543-9544

Ok YS, Chang SX, Gao B, Chung HJ (2015) SMART biochar technology - a shifting paradigm towards advanced materials and healthcare research. Environ Technol Innov 4:206-209

Rajapaksha AU, Chen SS, Tsang DCW, Zhang M, Vithanage M, Mandal S, Gao B, Bolan NS, Ok YS (2016) Engineered/designer biochar for contaminant removal/immobilization from soil and water: potential and implication of biochar modification. Chemosphere 148:276-291

Rondon MA, Lehmann J, Ramirez J, Hurtado M (2007) Biological nitrogen fixation by common beans (Phaseolus vulgaris L.) increases with bio-char additions. Biol Fertil Soils 43:699-708 
Schimmelpfennig S, Glaser B (2012) One step forward toward characterization: some important material properties to distinguish biochars. J Environ Qual 41:1001-1013

Wang L, O'Connor D, Rinklebe J, Ok YS, Tsang DCW, Shen Z, Hou D (2020) Biochar aging: mechanisms, physicochemical changes, assessment, and implications for field applications. Environ Sci Technol 54:14797-14814

Warnock DD, Lehmann J, Kuyper TW, Rillig MC (2007) Mycorrhizal responses to biochar in soil - concepts and mechanisms. Plant Soil 300:9-20

Woods WI, Falcao NPS, Teixeira WG (2006) Biochar trials aim to enrich soil for smallholders. Nature 443:144
Wu P, Ata-Ul-Karim ST, Singh BP, Wang HL, Wu TL, Liu C, Fang GD, Zhou DM, Wang YJ, Chen WF (2019) A scientometric review of biochar research in the past 20 years (1998-2018). Biochar 1:23-43

Yuan D, Yuan HJ, He XD, Hu HX, Qin SP, Clough T, Wrage-Monnig N, Luo JF, He XH, Chen M, Zhou SG (2021) Identification and verification of key functional groups of biochar influencing soil $\mathrm{N}_{2} \mathrm{O}$ emission. Biol Fertil Soil. https://doi.org/10.1007/s00374-02101541-9

Publisher's note Springer Nature remains neutral with regard to jurisdictional claims in published maps and institutional affiliations. 